\title{
Hubungan antara Love of Money, Machiavellian dengan Persepsi Etis: Analisis Berdasarkan Perspektif Gender
}

\author{
Rindayanti, Dekeng Setyo Budiarto \\ Universitas PGRI Yogyakarta \\ rendarindayati@gmail.com, dekengsb@upy.ac.id
}

\begin{abstract}
Ethical behavior is important since help educators and researchers understand future managers and executives' ethical behavior in organization. The research investigates the relationship between gender, love of money, machiavellian and ethic behavior. Data collected from 102 student of departemen of accounting. Result of the whole sample revealed that Machiavellian has significant effect on ethic behavior and there's different perception on ethic behavior based from gender.
\end{abstract}

Key Words: love of money, machiavellian, ethic behavior, gender.

\begin{abstract}
Perilaku etis penting karena dapat membantu pendidik dan peneliti untuk memahami perilaku manajer dan eksekutif dalam organisasi di masa yang akan dating. Penelitian ini menguji hubungan antara gender, love of money, machiavellian dan perilaku etis mahasiswa. Sampel penelitian adalah 102 mahasiswa jurusan Akuntansi. Hasil penelitian membuktikan bahwa machiavellian berpengaruh signifikan terhadap perilaku etis mahasiswa. Selain itu terdapat perbedaan yang signifikan pada perilaku etis berdasarkan gender.
\end{abstract}

Kata kunci: love of money, machivellian, perilaku etis, gender

Diterima: 16 April 2017; Revisi: 20 Juli 2017; Disetujui: 14 Agustus 2017 


\section{PENDAHULUAN}

Terungkapnya beberapa skandal oleh perusahaan besar yang melibatkan akuntan mengakibatkan kepercayaan masyarakat terhadap perilaku etis akuntan menurun. Kasus Enron membuktikan bahwa perilaku etis yang dimiliki akuntan merupakan sesuatu yang sangat penting (Tang et al., 2008). Riset yang meneliti perilaku etis telah banyak dilakukan oleh peneliti sebelumnya. Beberapa riset telah meneliti perilaku etis dan menghubungkan dengan variable lain sepertiteori reasoned action (Uddin \& Gillett 2002); love of money, machiavellianism, risk tolerance, religiosity (Tang et al., 2008: Walker et al., 20I2: Singhapakdi et al, 20I3: Hogue et al., 20I3); sufisme dalam Islam (Sidani \& Ariss, 20I5); gender (Westbrook et al, 20II).

Meskipun riset yang meneliti perilaku etis telah banyak dilakukan, namun penelitian ini masih menarik karena: Pertama, pendidikan etika kemungkinan gagal karena pelanggaran etika masih banyak dilakukan oleh penjahat kerah putih dengan status sosial dan pendidikan yang tinggi (Tang 2016). Kedua, pelanggaran etika tidak disebabkan karena tingkat intelegensi yang rendah namun karena kearifan yang rendah (lack of wisdom) (Feiner, 2004: Tang et al 2008). Ketiga, perilaku etis merupakan tantangan ke depan bagi perguruan tinggi sehingga memiliki metode yang tepat untuk meningkatkan etika mahasiswanya (Jurkiewicz et al, 2004). Keempat, perilaku etis dapat berubah sebelum dan sesudah bekerja terutama berkaitan dengan gender (Westbrook et al, 20II).

Tujuan penelitian ini selain menguji pengaruh love of money dan machiavellian terhadap perilaku etis adalah menguji love of money, machivellian dan perilaku etis berdasarkan gender. Hasil penelitian diharapkan dapat memberikan masukan bagi pendidik untuk memperbanyak muatan etika dalam mata kuliah akuntansi. Selain itu, hasil penelitian ini dapat memberikan tantangan bagi peneliti untuk mengungkapkan berbagai masalah yang dihadapai akuntan berkaitan dengan pelanggaran etika.

\section{KAJIAN KEPUSTAKAAN}

BerdasarkanTheory of Reasoned Action (TRA) perilaku merupakan fungsi dari niat perilaku yangselanjutnya ditentukan oleh sikap terhadap tindakan dan norma sosial 
(Ajzen \& Fishbein, 1980).Pendidik dan peneliti saat ini menghadapi fase krisis yang menghawatirkan berkaitan dengan perilaku etis, hal ini tidak hanya tantangan bagi dunia bisnis, namun juga peluang bagi akademis untuk memperkuat muatan etika pada pendidikan (Tang et al, 2008).

Beberapa riset sebelumnya (Tang et al 2008; Tang \& Chen, 2008; Tang 2016) menjelaskan bahwa perilaku etis berkaitan dengan sifat love of money dan machiavellian. Sebagai instrumen perdagangan, uang sangat penting sehingga dapat mempengaruhi perilaku atau sikap seseorang (Tang, 2016). Seseorang yang memiliki sikap cinta uang berlebih, akan menganggap uang sebagai kebutuhan yang harus dipenuhi dan akan melakukan berbagai cara untuk mendapatkan uang (Robbins \& Judge, 2007; Noviani \& Andri , 20I4). Penelitian Erlintan (2014) dan Toriq (2015) Singhapakdi et al, (2013); Tang (2016) menyatakan bahwa love of money mempunyai pengaruh yang signifikan terhadap perilaku etis. Persepsi terhadap love of money yang tinggi akan menurunkan perilaku etis sedangkan persepsi love of money yang rendah akan meningkatkan perilaku etis. Hipotesis yang akan diuji adalah sebagai berikut:

\section{HI: Love of money berpengaruh negatif terhadap persepsi etis mahasiswa akuntansi}

Perilaku machiavellian memiliki karakteristik yaitu: rendahnya komitmen ideology, kurangnya hubungan interpersonal dan memiliki sikap kurang perhatian terhadap orang lain (Tang et al, 2008). Kepribadian seseorangmempengaruhi perilaku etis. Machiavellianisme membentuk suatu tipe kepribadian yang disebut sifat machiavellian, serta pertimbangan etisperilaku individu dalam menghadapi perilaku etis. Seseorang yang memiliki sifat machiavellian tinggi, memungkinkan untuk berperilaku tidak etis (Richmond, 2003). Perilaku machiavellian merupakan persepsi yang mendasari hubungan antar personal. Persepsi ini menjadi dasar dalam membentuk kepribadian seseorang untuk menjalin hubungan dengan orang lain (Erlintan, 20l4). Berdasarkan hasil penelitian di atas maka dapat disimpulkan bahwa perilaku machiavellian berpengaruh negatif dan signifikan terhadap persepsi etis mahasiswa. Hipotesis yang akan diuji adalah sebagai berikut: 


\section{H2: Machiavellian berpengaruh negatif terhadap persepsi etis mahasiswa akuntansi}

Perilaku love of money merupakan pemicu berbagai krisis etika karena: I) uang merupakan alat utama untuk memotivasi karyawan; 2) uang merupakan ukuran yang paling mudah untuk menilai kinerja perusahaan; 3) uang merupakan ukuran kesejahteraan bagi sebagian besar pegawai (Singhapakdi et al, 20I3). Uang merupakan motivasi sehingga mempengaruhi perilaku seseorang, seseorang yang memiliki keterbatasan keuangan akan terobsesi degan uang. Uang dapat memberikan efek positif yaitu memotivasi seseorang untuk meningkatkan kinerja, namun juga memiliki efek negatif untuk melakukan kecurangan sehingga memperoleh tambahan bonus berupa uang (Tang et al 2008).

Machiavellianadalah kondisi dimana seorang individu yang bekerja secara agresif, manipulatif, eksploitatif, dan curang untuk mencapai tujuan tanpa memperhatikan perasaan, hak, dan kebutuhan orang lain (Tang et al, 2008). Studi tentang machiavellian pertamakali dilakukan oleh Christie \& Geis (1970) yang menjelaskan mahwa machiavellian adalah sikap yang mengesampingkan kehormatan, kesopanan dan kepercayaan serta dapat melakukan eksploitasi sehingga sikap ini akan meningkatkan ketidakjujuran seseorang (Hogue et al, 2013). Machiavellian berkaitan dengan gender terutama laki-laki, seseorang yang memiliki tingkat machiavellian akan lebih berani melanggar etika untuk mencapai tujuannya (Tang et al, 2008)

Riset sebelumnya menjelaskan bahwa laki-laki memiliki kecintaan terhadap uang yang lebih tinggi dibandingkan perempuan sehingga lebih berani melakukan tindakan machiavellian dan perilaku tidak etis (Tang \& Chen, 2008). Riset lain menemukan bahwa perempuan lebih kooperatif daripada laki-laki, sedangkan laki-laki lebih menunjukkan sikap agresif dan mempunyai daya saing. Perbedaan ini dapat djelaskan dengan menggunakan teori peran sosial yang disebut gender stereotype yang menjelaskan bahwa laki-laki dan wanita cenderung bertindak dengan cara yang berbeda.Studi terakhir mengungkapkan bahwa perempuan lebihmenggunakan pendekatan etis untuk menyelesaikan masalah bisnissementara laki-laki lebih mementingkan kompetisi(Babladelis et al, 1983; Eagly, 1987; Miller \& Karakowsky, 2005; Burns, 1999; Wilborn et al, 2007 \& Rittenburg, 2007; Westbrook et al, 20II). Selain itu wanita 
memiliki kejujuran lebih baik sementara laki-laki memiliki sifat machiavellian lebih tinggi (Hogue et al, 20I3). Hipotesis yang akan diuji adalah sebagai berikut:

$\mathrm{H} 3 \mathrm{a}$ : terdapat perbedaan tingkat love of moneyberdasargender

$\mathrm{H} 3 \mathrm{~b}$ : terdapat perbedaan tingkat machiavellian berdasar gender

$\mathrm{H} 3 \mathrm{c}$ : terdapat perbedaan tingkat persepsi etis berdasar gender

\section{METODE}

Sampel penelitian ini adalah mahasiswa, hal ini penting karena berdasarkan penelitian Tang (2016) tujuan mahasiswa melanjutkan studi adalah untuk mencapai tujuan utama yaitu menjadi orang yang sukses, memiliki kedudukan dan kaya bukan untuk meningkatkan perilaku etis.Data penelitian dikumpulkan dengan menyebarkan kuesioner kepada mahasiswa prodi akuntansi Universitas PGRI Yogyakarta dengan teknik stratified random sampling. Prodi akuntansi Universitas PGRI Yogyakarta memiliki mahasiswa sebanyak 569. Target penelitian sebesar $20 \%$ dari jumlah mahasiswa prodi akuntansi Universitas PGRI Yogyakarta (I20 responden). Penyebaran kuesioner terdiri dari 33 kuesioner diberikan kepada mahasisa akuntansi semester III, 2I kuesioner diberikan kepada mahasisa akuntansi semester $\mathrm{V}$, dan 7/ kuesioner diberikan kepada mahasisa akuntansi semester VII. Kuesioner yang berhasil dikumpulkan sebanyak 125, kuesioner yang dapat digunakan sebanyak 102 kuesioner $(81,6 \%), 23$ kuesioner (18,4\%) tidak dapat digunakan karena jawaban yang tidak lengkap (Tabel I).

\section{Tabel I. Deskripsi Responden}

\begin{tabular}{llccccc}
\hline No & Gender & \multicolumn{3}{c}{ Semester } & Jumlah & Prosentase \\
\cline { 3 - 5 } & & III & V & VII & & \\
\hline I & Laki-laki & 7 & 4 & II & 22 & $21,6 \%$ \\
2 & Perempuan & 22 & I7 & $4 \mathrm{I}$ & 80 & $78,4 \%$ \\
\hline
\end{tabular}

Sumber: data primer diolah, 2016

Variabel dependen penelitian ini adalah perilaku etis yang diukur menggunakan 4 skenario. Mahasiswa akan menjawab pertanyaan melalui 4 buah kasus dalam situasi sebagai seorang manager berkaitan dengan fraud sebagai berikut: (I) Perusahaan mengadapi kegagalan yang mengakibatkan pendapatan menurun sehingga manajer dapat melakukan menajemen laba untuk mempertahankan kinerja perusahaan; (2) Perusahaan 
menghadapi perubahan pasar yang mengakibatkan banyak kehilangan pelanggan sehingga manajer dapat memodifikasi current ratio; (3) Manajer memodofikasi persediaan untuk meningkatkan laba perusahaan sehingga dapat memperoleh bonus akhir tahun; (4) Perusahaan menghadapi dampak krisis di Asia sehingga pendapatan menurun, hal ini mendorong manajer untuk mengakui pendapatan yang belum diterima.

Variabel gender dalam penelitian ini diukur menggunakan variable dummy yaitu I untuk laki-laki dan 0 untuk wanita (Tang \& Chen, 2008).Selanjutnya variable gender digunakan untuk menguji perbedaan persepsi pada variabel love of money, maciavellian dan perilaku etis mahasiswa.

Pada penelitian ini Love of moneymerupakan perilaku seseorang yang menganggap uang sebagai kekayaan, motivasi dan sesuatu yang sangat penting. Love of money diukur dengan 4 indikator yaitu uang merupakan ukuran kesuksesan, uang sebagai motivasi, uang sebagai lambang kekayaan dan uang merupakan sesuatu yang sangat penting (Tanget al, 2008; Singhapakdi, 2013). Jawaban diukur dengan skala tujuh poin, I (sangat tidak setuju) sampai dengan 7 (sangat setuju).

Machiavellian memiliki kecenderungan yang negatif yaitu menunjukkan cara yang tidak etis dengan memanipulasi sesuatu untuk mencapai tujuan. Machiavellian diukur menggunakan 4 item pernyataan dengan 2 indikator yaitu tactics dan human nature (Tang \&Chen, 2008). Jawaban diukur dengan skala tujuh poin, I (sangat tidak setuju) sampai dengan 7 (sangat setuju).

\section{HASIL PENELITIAN DAN PEMBAHASAN}

\section{Pengujian Instrumen}

Pengujian instrumen pada penelitian ini menggunakan uji validitas dan uji reliabilitas. Instrumen yang valid berarti alat ukur yang digunakan untuk mendapatkan data (mengukur) itu valid. Valid berarti instrumen dapat digunakan untuk mengukur apa yang seharusnya diukur (Sugiyono, 2010:172). Hasil uji validitas menunjukkan bahwa seluruh variabel penelitian yaitu love of money, Machiavellian, dan persepsi etis adalah valid. Contoh hasil uji validitas persepsi etis ditunjukkan pada Tabel 2. 
Tabel 2. Hasil Uji Validitas Variabel Perilaku Etis

\begin{tabular}{lcc}
\hline Instrumen & P Value & Keterangan \\
\hline Instrumen $y . I$ & $0,000^{* *}$ & Valid \\
Instrumen $y .2$ & $0,000^{* *}$ & Valid \\
Instrumen $y .3$ & $0,000^{* *}$ & Valid \\
Instrumen $y .4$ & $0,000^{* *}$ & Valid \\
\hline
\end{tabular}

Ket: ${ }^{* *}$ signifikansi < 1\%, sumber: data primer diolah, 2016

Instrumen yang reliabel adalah Instrumen yang digunakan beberapa kali untuk mengukur obyek yang sama, akan menghasilkan data yang sama (Sugiyono, 2010:172). Hasil dari pengujian reliabilitas (Tabel 4) menunjukkan bahwa seluruh variabel penelitian memiliki nilai Cronbach Alpha lebih dari 0,6.

Tabel 4. Hasil Uji Reliabilitas

\begin{tabular}{lccc}
\hline \multicolumn{1}{c}{ Variabel } & Item & $\begin{array}{c}\text { Cronbach } \\
\text { Alpha }\end{array}$ & Keterangan \\
\hline Love of money & XII-XII8 & 0,794 & Reliabel \\
Machiavellian & $\mathrm{X} 2 \mathrm{I}-\mathrm{X} 24$ & 0,656 & Reliabel \\
Persepsi etis & YII-YI4 & $0,61 \mathrm{I}$ & Reliabel \\
\hline
\end{tabular}

Sumber: data primer diolah, 2016

\section{Pengujian Hipotesis}

Pengujian hipotesis I dan hipotesis 2 dilakukan untuk menguji pengaruh love of money dan Machiavellian terhadap perilaku etis (tabel 5), sedangkan pengujian hipotesis 3 dilakukan untuk menguji apakah terdapat perbedaan antara persepsi love of money, machiavellian dan perilaku etis berdasarkan gender (table 6).

Tabel 5. Hasil Uji t (hipotesis I dan 2)

\begin{tabular}{lccl}
\hline \multicolumn{1}{c}{ Variabel } & $\mathrm{B}$ & $\mathrm{P}$ Value & Hasil \\
\hline Love of money & 0,240 & 0,373 & $\mathrm{H}$ : ditolak \\
Machiavellian & $-0,593$ & $0,025^{*}$ & $\mathrm{H} 2$ : diterima \\
\hline F Hitung $=4,648$ & $0,012^{*}$ & \\
Adjusted $R$ Square $=0,067$ & & & \\
\hline \multicolumn{4}{c}{ Ket: $*$ signifikansi $<5 \%$, sumber: data primer yang diolah, 2016}
\end{tabular}

Berdasarkan Tabel 5 dapat dijelaskan bahwa Love of moneytidak berpengaruh terhadap perilaku etis mahasiswa akuntansi dengan $p$ value $>0,05(0,373)$. Perilaku love 
of money dibentuk dari berbagai tempat seperti keluarga, masyarakat, dan tempat ibadah, sehingga pendidik mengalami kesulitan untuk menemukan metode yang tepat untuk meningkatkan perilaku etis terutama berkaitan dengan love of money (Tang et al, 2008). Sesuai dengan hasil riset sebelumnya bahwa tujuan kuliah untuk mencapai kesuksesan dan memiliki banyak uang (Tang, 2016) karena uang merupakan ukuran kesejahteraan seseorang (Singhapakdi et al, 2013) namun mahasiswa masih dapat menjaga etika.

Machiavellian berpengaruh terhadap persepsi etis mahasiswa akuntansi dengan $\mathrm{P}$ value $<0.05$ (0.025). Perilaku Machiavellian yang ditunjukkan oleh mahasiswa berpengaruh negatif pada perilaku etis mahasiswa. Ketika menghadapi situasi yang memerlukan keputusan yang melibatkan tanggungjawab sosial maka mahasiswa akan berusaha untuk melakukan rekonseptualisasi terhadap keputusan etis (Tang \& Chen, 2008). Apabila diperlukan maka sikap Machiavellian mahasiswa akan muncul untuk melakukan pelanggaran etika sehingga semua tujuan dapat tercapai.

Tabel 6. Hasil Uji Independent-Samples t test (hipotesis 3)

\begin{tabular}{lcccccc}
\hline \multirow{2}{*}{ Variabel } & \multicolumn{2}{c}{ Laki-laki } & \multicolumn{2}{c}{ Wanita } & \multirow{2}{*}{ P Value } & Hasil \\
\cline { 2 - 5 } & Mean & S. Dev & Mean & S. Dev & & \\
\hline $\begin{array}{l}\text { Love } \\
\text { money }\end{array}$ & 3,00 & 0,82 & 3,15 & 0,57 & 0,429 & Hla: ditolak \\
Machiavellian & 2,91 & 0,67 & 2,90 & 0,66 & 0,780 & HIb: ditolak \\
Persepsi etis & 4,46 & 0,82 & 5,19 & 0,88 & $0,000^{* *}$ & HIc: diterima \\
\hline
\end{tabular}

Ket: ** signifikansi <1\%, sumber: data primer diolah, 2016

Berdasarkan Tabel 6 dapat disimpulkan bahwa tidak terdapat perbedaan antara laki-laki dan perempuan dalam menentukan perbedaan tingkat love of money, dan machiavellian. Nilai $P$ valuevariabel love of money sebesar $0,429>0,05$ dan variabel machiavellian sebesar $0,780>0,05$ berarti $\mathrm{H} 3 \mathrm{a}$ dan $\mathrm{H} 3 \mathrm{~b}$ tidak terbukti. Sesuai dengan temuan sebelumnya O'Leary \& Depner 1975; Westbrook et al, 20II) yang menjelaskan bahwa kompetensi, kesuksesan dan rasionalitas laki-laki dan wanita tidak banyak berubah dari masa anakanak sampai dengan dewasa. Persepsi laki-laki dan wanita terhadap love of money dan 
machiavellian tidak berbeda karena mahasiswa masih memiliki kecenderungan materialistis, namun persepsi ini akan berubah sesuai dengan kondisi lingkungan dan pekerjaan

Nilai $P$ value variabel persepsi etis $0,000<0,05$ berarti $\mathrm{H} 3 \mathrm{c}$ dapat dibuktikan artinyaterdapat peredaan perilaku etis mahasiswa berdasar gender.Kondisi ini terjadi karena persepsi etis pada laki-laki cenderung rendah sebaliknya wanita cenderung lebih sensitif terhadap perilaku etis (Musbah et al, 2016). Sesuai dengan riset Tang \& Tang (2010) yang menyatakan bahwa laki-laki cenderung lebih acuh pada peringatan atau larangan dari orangtua maupun guru. Seseorang yang memiliki daya saing (personal development competitiveness) yang tinggi 1 ebih berprestasi, pekerja keras, mandiri, memiliki semangat untuk sukses dalam bentuk material, menerima tantangan dan resiko serta menjalani hidup dengan semangat. Konektivitas perempuan lebih membutuhkan keterlibatan, perdamaian, dan loyalitas, sedangkan laki-laki memiliki keinginan menaklukkan yang tinggi, lebih berprestasi, rasa hormat dan kemandirian (Ryckman et al, 1997 \& Enggerichs, 2004; Westbrook et al, 20II).

\section{SIMPULAN}

Berdasarkan hasil analisis data yang dilakukan dapat diambil kesimpulan bahwa Love of moneytidak berpengaruh signifikan terhadap perilaku etis mahasiswa akuntansi sedangkan machiavellian berpengaruh signifikan terhadap perilaku etis mahasiswa. Selain itu tidak terdapat perbedaan tingkat love of money dan machiavellian berdasar gender, namun terdapat perbedaan tingkat perilaku etis berdasar gender.

Penelitian terhadap mahasiswa menunjukkan bahwa terdapat perbedaan tingkat persepsi etis berdasar gender, saran untuk penelitian selanjutnya yaitu menambahkan responden yang sudah berkerja. Mahasiswa sebelum bekerja menunjukkan perbedaan perilaku dalam mengambil keputusan berdasarkan gender, tetapi setelah bekerja tidak terdapat perbedaan perilaku dalam pengambilan keputusan berdasar gender karena terjadi proses seleksi profesional yang menghilangkan perbedaan perempuan dari pekerjaan (Robin \& 
Babin, 1997; Westbrook et al, 201I). Penelitian selanjutnya juga disarankan untuk menambah variabel ethic training karena penilaian etika seseorang dapat dibentuk melalui ethic training (Singhapakdi et al, 2013); mengukur persepsi etika berdasarkan program studi karena perbedaan kurikulum dapat mengakibatkan perbedaan perilaku etis mahasiswa (Tang et al., 2008).

\section{PUSTAKA ACUAN}

Ajzen, I \& Fisbein, M. 1980. Understanding Attitudes and Predicting Social Behavior. New Jersey: Prentice-Hall.Englewood Cliffs.

Erlintan DN. 2014. Pengaruh Love of Money dan Perilaku Machiavellian terhadap Persepsi Etis Mahasiswa Akuntansi. Jurnal Profita. Hal 6885.

Feiner, M. 2004. The Feiner Points of Leadership." Warner Business Books, New York, NY

Hogue, M. Levashina, J. \& Hang, H. 2013. Will I feke It? The Interplay of Gender, Machiavellianism, and Self-monitoring on Strategies for Honesty in Job Interviews. Journal of Business Ethics. 117: 399$4 \mathrm{II}$.

Jurkiewicz, CL. Giacalone, RA. \& Knouse, SB. 2004. Transforming Personal Experience into Pedagogical Tool: Ethical Complaints. Journal of Business Ethics. 53: 283-95

Musbah, A. Cowtown, CJ. \& Tyfa, D. 2016. The Role of Individual Variables, Organizational Variables and Moral Intensity Dimensions in Libyan Management Accountan's Ethical Decision Making. Journal of Business ethics. 134: 335-358.

Noviani R \& Andri P. (20/4). Analisis Pengaruh Love of Money terhadap Persepsi Etis Mahasiswa Akuntansi. Diponegoro Journal of Accounting. 3 (3): $1-12$.

O'Leary, VE. \& Depner, C. 1975. College Males Ideal Female: Changes in Sex-Role Stereotype.”The Journal of Social Psychology.95: 40-193. 
Richmond, K. 2003. Ethical Reasoning, Machiavellian Behavior, and Gender: The Impact on Accounting Students' Ethical Decision Making. Ph.D Dissertation .Virginia Polytechnic Institute.

Sidani, Y. \& Ariss, A. 2015. New Conceptual Foundations for Islamic Business Ethics: The Contribution of Abu Hamid Al-Ghazali. Journal of Business Ethics. 129: 847857.

Singhapakdi, A. Vitell, SJ. Lee, DJ. Nisius, AM \& Yu, GB. 2012. The Influence of Love of Money and Religiosity on Ethical Decisionmaking in Marketing. Journal of Business Ethics. I14: 183-191.

Sugiyono. 2010. Metode penelitian bisnis" (pendekatan kuantitatif, kualitatif, dan $R$ \& D). Bandung: Alfabeta.

Tang, TL. 2016. Theory of Monetary Intelligence : Money Attitudes-religious Values, Making Money, Making Ethical Decisions and Making the Grade. Journal of business Ethics. 133: 583-603.

Tang, TL. \& Tang, TL. 2010. Finding the Lost Sheep: A Panel Study of Business Students' Intrinsic Religiosity, Machiavellianism, and Unethical Behavior Intention in a Public Institution. Ethics and Behavior. 20. (5): 352379.

Tang, TL., Chen, YJ\& Sutarso, T. 2008. Bad Apples in Bad (Business) Barrels: the Love of Money, Machiavellianism, Risk Tolerance, and Unethical Behavior. Management Decision. 46 (2): 243-63

Tang, TL.\& Chen, Y. 2008. Intelligence vs. Wisdom: The Love of Money, Machiavellianism, and Unethical Behavior across College Major and Gender. Journal of Business Ethics.82: I-26.

Toriq IA. 20I5. Pengaruh Love of Money dan Machiavellian terhadap Persepsi Etis Mahasiswa Akuntansi. Jurnal Nominal. 4(2): 31-44

Uddin, N \& Gillet, PR. 2002. The Effect of Moral Reasoning and Self Monitoring on CFO Intentions to Report Fraudulently on Financial Statement. Journal of Business Ethics. 40: 15-32.

Walker, AG. Smither, JW.DeBode, J. 2012. The Effect of Religiosity on Ethical Judgments. Journal of Business Ethics. 106: 437-452.

Westbrook, KW. Arendall, CS.\& Padelford, WM. 20II. Gender, Competitiveness, 
Hubungan antara Love of Money

Rindayanti, Dekeng Setyo Budiarto

and Unethical Negotiation Strategis. Gender in Management: International Journal. 26 (4): 289-3I0. 